\title{
STUDI KUAT TEKAN BETON SPEEDCRETE DENGAN ZAT ADDITIVE NAPHTHALENE BERDASARKAN VARIASI UMUR
}

\author{
Syifa Fauziah', Anisah ${ }^{2}$, Sittati Musalamah ${ }^{3}$ \\ ${ }^{12,3}$ Pendidikan Teknik Bangunan, FT, UNJ \\ Email: smusalamah@unj.ac.id
}

\begin{abstract}
ABSTRAK
Penelitian ini bertujuan untuk mengetahui nilai kuat tekan maksimum beton speedcrete menggunakan aditif aditif naphthalene pada setiap umur pengujian dan membandingkan dengan beton normal 28 hari. Penelitian ini dilakukan di Lab Beton PT. Torsina Redikon Pulogadung dengan metode eskperimen. Penelitian ini menggunakan benda uji berbentuk silinder dengan diameter $15 \mathrm{~cm}$ dan tinggi $30 \mathrm{~cm}$. Pengujian kuat tekan beton speedcrete menggunakan alat Crushing Test Machine. Dalam penelitian ini kuat tekan dihasilkan dengan menggunakan superplasticizer jenis naphthalene dan dibandingkan dengan beton normal tanpa menggunakan aditif. Rencana mutu sasaran adalah $f c$ ' 35 MPa dengan dosis penggunaan aditif 1,7\% dari berat semen. Hasil penelitian menunjukkan peningkatan nilai kuat tekan beton speedcrete dengan penambahan material naftalena semakin meningkat seiring dengan bertambahnya umur beton. Hasil penelitian menunjukkan bahwa kuat tekan beton speedcrete dengan bahan aditif naftalena $12 \mathrm{jam}, 18 \mathrm{jam}, 28$ jam dan 48 jam adalah 0,5 MPa, 17,81 MPa, 31,14 MPa dan 45,77 MPa. Kuat kuat beton normal dengan penambahan 20\% umur air 28 hari yaitu sebesar 54,76 MPa.
\end{abstract}

Kata Kunci: Variasi Umur, Beton Speedcrete, Kuat Tekan

\begin{abstract}
This research aims to determine the maximum compressive strength value of concrete speedcrete using naphthalene additive additive at each test age and compare with normal concrete 28 days. This research was conducted at concrete Lab of PT. Torsina Redikon Pulogadung with eskperimen method. This research used cylindrical test object with diameter $15 \mathrm{~cm}$ and height $30 \mathrm{~cm}$. . Testing compressive strength of concrete speedcrete using Crushing Test Machine tool. In this research the compressive strength was produced by using superplasticizer type naphthalene and compared with normal concrete without using additive. The target quality plan is $f_{c}$ '35 MPa with the use of additive dose of $1.7 \%$ of the weight of cement. The results of this research showed an increase in the value of compressive strength of concrete speedcrete with aadditive materials added naphthalene increased with increasing age of concrete. The results showed that the compressive strength of concrete speedcrete with naphthalene additive materials of 12 hours, 18 hours, 28 hours and 48 hours was 0.5 $\mathrm{MPa}, 17,81 \mathrm{MPa}, 31,14 \mathrm{MPa}$ and 45,77 MPa. Normal strength concrete strength with the addition of $20 \%$ water age 28 days that is equal to $54.76 \mathrm{MPa}$.
\end{abstract}

Keywords : Age Variation, Speedcrete Concrete, Compressive Strength 


\section{PENDAHULUAN}

Beton adalah bahan yang banyak digunakan pada pembangunan dibidang konstruksi sekarang ini, baik pada bangunan gedung, jembatan, bendungan, maupun konstruksi lainnya. Beton dikatakan sebagai suatu campuran dari empat bahan dasar terpisah, yaitu: semen, agregat kasar, agregat halus, dan air. Berdasarkan definisi lain, beton dapat juga dikatakan sebagai campuran bergradasi dari agregat halus dan agregat kasar yang direkatkan bersama-sama oleh pasta semen. Metode pembuatan campuran beton harus memperhatikan hal-hal berikut yaitu proses pengerjaan yang mudah (workability), kekuatan beton yang dihasilkan (strength), keawetan beton (durability), dan harga yang ekonomis. Jakarta merupakan kota padat penduduk, sehingga sering terjadi kemacetan yang diantaranya disebabkan oleh kerusakan jalan atau sedang ada proses konstruksi jalan, maka dari itu dibutuhkan proses konstruksi jalan yang cepat. Dengan semakin pesatnya pertumbuhan pengetahuan dan teknologi dibidang konstruksi terciptalah beton yang cepat mengeras (speedcrete).

Speedcrete diperkenalkan di Indonesia pada tahun 2009. Pada umumnya speedcrete difokuskan pada konstruksi jalan raya, seperti patching (penambalan). Speedcrete merupakan konsep revolusioner yang memberikan berbagai keuntungan baru untuk kontraktor dan kebutuhan publik. Keuntungan utama dari speedcrete adalah proses yang cepat dengan kualitas terbaik sehingga menghemat waktu. (Hayyu, 2009).

Terdapat berbagai macam speedcrete sesuai dengan zat additive yang digunakan. Zat additive berfungsi untuk meningkatkan mutu dan mempercepat proses pengerasan dalam pembuatan beton, dan tipe zat additive tersebut yaitu tipe $\mathrm{F}$ (superplasticizer). Terdapat empat jenis superplasticizer diantaranya Sulfonated Melamine Formaldehyde Condensates (SMF) dengan kandungan klorida 0,005\%, Sulfonated Naphthalene Formaldehyde Condensates (SNF) kandungan klorida yang diabaikan, Modified Lig nosulfonates tanpa kandungan klorida dan Polycarboxilate Ethers yaitu superplasticizer yang biasa digunakan pada beton pracetak dan menambah nilai workability secara signifikan. Superplasticizer yang digunakan adalah sulfonated naphthalene formaldehyde (SNF) (Mulyono, 2007).

Naphthalene adalah hidrokarbon kristalin aromatik berbentuk padatan berwarna putih dengan rumus molekul $\mathrm{C}_{10} \mathrm{H}_{8}$ dan berbentuk dua cincin benzena yang bersatu (Gusva. 2013). Menurut Chinacays Pei (2017) superplasticizer seri naphthalene ini merupakan superplasticizer dengan tingkat reduksi air yang tinggi (15\% sampai 25\%), tidak ada efek pemberian udara, sedikit efek pada waktu pengaturan, yang relatif sesuai dengan kualitas semen, harganya relatif murah, naphthalene superplasticizer sering digunakan dalam pembuatan high strength, high performance concrete.

Beberapa penelitian yang sudah
dilakukan tentang penggunaan
superplasticizer pada beton cepat
mengeras (speedcrete) yaitu telah
dilakukan oleh Irman Susandi tahun 2013
tentang tinjauan kuat tekan beton ringan
menggunakan mix design speedcrete
dengan bahan tambah sika viscocrete-10.
Umur yang digunakan pada penelitian ini
yaitu 1 hari, 3 hari, 7 hari, 14 hari, dan 28
hari. Hasil penelitian ini beton ringan
speedcrete dengan bahan tambah sika
viscocrete-10 umur 1 hari sudah mencapai
beton normal 28 hari. Penelitian lain
tentang superplasticizer juga sudah
dilakukan oleh Seti dan Nadia tahun 2012
tentang analisis pengaruh beton dengan
bahan admixture naphthalene dan
polycarboxilate terhadap kuat tekan beton


normal. Umur yang digunakan pada penelitian ini adalah 3 hari, 7 hari, 14 hari, dan 28 hari. Dari penelitian tersebut diketahui jika speedcrete superplasticizer tipe polycarboxilate menghasilkan peningkatan kuat tekan yang lebih tinggi dari speedcrete superplasticizer tipe naphthalene dan beton normal pada umur beton yang sama.

Pada umumnya beton membutuhkan waktu minimal 14 hari untuk mencapai kekuatan tekan karakteristik yang diinginkan, sementara speedcrete hanya membutuhkan waktu 7 jam sampai dengan 24 jam tergantung zat additive dan dosis yang digunakan (Reni, 2013). Percepatan dalam pembangunan menuntut para praktsi konstruksi agar mereka dapat menyelesaikan proyekproyek yang berhubungan dengan pengecoran dapat digunakan sesegera mungkin. Contohnya dalam hal perbaikan jalan yang memerlukan waktu cepat. Seperti halnya di kota-kota besar seperti jalan-jalan protokol di Jakarta, mengingat sering terjadinya kemacetan akibat jalan rusak sehingga menyulitkan untuk perbaikan jalan.

Atas dasar pertimbangan tersebut, dan juga dilihat dari beberapa penelitian yang dilakukan sebelumnya bahwa bahan tambah additive naphthalene dapat mempercepat pengerasan beton Pada penelitian ini akan ditinjau hasil kuat tekan beton speedcrete umur 24 jam tercapai mutu fc' rencana dan dibandingkan dengan beton normal umur 28 hari. Maka dari itu dilakukan penelitian mengenai nilai kuat tekan speedcrete zat additive naphthalene dengan penggunaan dosis $1,7 \%$ dari berat semen dan fc' 35 Mpa diduga masih dalam hitungan jam, dan dibandingkan dengan nilai kuat tekan beton normal umur 28 hari. Dengan variasi umur speedcrete 12 jam, 18 jam, 24 jam, dan 48 jam, sedangkan variasi umur untuk beton normal 7 hari, 14 hari dan 28 hari. Perbandingan umur ini didapat dari hasil umum optimum yang didapat dari penelitian sebelumnya.

\section{METODE}

\subsection{Metode Penelitian}

Metode penelitian yang akan digunakan dalah metode eksperimen, dengan benda uji berbentuk silinder dengan diameter $15 \mathrm{~cm}$ dan tinggi $30 \mathrm{~cm}$ yang dibuat dengan membuat beton speedcrete menggunakan bahan tambah additive naphthalene. Umur pengujian beton yaitu umur 12 jam, 18 jam, 24 jam, dan 48 jam untuk beton speedcrete, dan beton normal pada 7 hari, 14 hari dan 28 hari.

\subsection{Teknik Pengambilan Sampel}

\subsubsection{Sampel}

Sampel yang akan diuji dalam penelitian berjumlah 21 buah merupakan keseluruhan dari sampel, yang terdiri dari 12 benda uji untuk beton speedcrete dan 9 benda uji untuk beton normal. Dimana jumlah sampel yang dipakai sesuai dengan SNI 03-2847-2002 tentang Tata Cara Perencanaan Struktur Beton Untuk Bangunan Gedung, dan SNI 2458:2008 Tentang Tata Cara Pengambilan Contoh Beton Segar.

\section{Tabel Pengambilan Sampel}

\begin{tabular}{|c|c|c|c|}
\hline \multicolumn{2}{|c|}{$\begin{array}{l}\text { Beton Speedcrete } \\
\text { dengan Additive } \\
\text { Naphthalene }\end{array}$} & \multicolumn{2}{|c|}{$\begin{array}{l}\text { Beton Normal } \\
\text { Tanpa Additive } \\
\text { Naphthalene }\end{array}$} \\
\hline Umur & $\begin{array}{l}\text { Jumlah } \\
\text { Benda } \\
\text { Uji }\end{array}$ & Umur & $\begin{array}{c}\text { Jumlah } \\
\text { Benda } \\
\text { Uji }\end{array}$ \\
\hline 12 jam & 3 & 7 hari & 3 \\
\hline 18 Jam & 3 & 14 hari & 3 \\
\hline 24 Jam & 3 & 28 hari & $3 \mathrm{i}$ \\
\hline 48 Jam & 3 & & \\
\hline TOTAL & 12 & TOTAL & 3 \\
\hline
\end{tabular}




\subsection{Prosedur Penelitian}

\subsubsection{Tahap Persiapan}

Dalam persiapan penelitian ini dilakukan segala hal yang mendukung terlaksananya proses penelitian. Dimulai dari pemeriksaan material dan peralatan yang akan digunakan dalam penelitian, dan penentuan hari kerja penelitian.

\subsubsection{Tahap Pemeriksaan Bahan}

Sebelum bahan-bahan yang sudah tersedia digunakan dalam penelitian, maka harus dilakukan pemeriksaan terhadap bahan-bahan tersebut. Adapun pemeriksaan terhadap tiap-tiap bahan dapat dijabarkan sebagai berikut :.

\subsubsection{Agregat Halus}

a. Pengujian Kadar Lumpur

b. Pengujian Analisis Saringan

c. Pengujian Berat Jenis dan Penyerapan

d. Pengujian Kadar Air

\subsubsection{Agregat Kasar}

a. Pengujian Analisis Saringan

b. Pengujian Berat Jenis dan Penyerapan

c. Pengujian Kadar Air

\subsubsection{Air}

Air pada penelitian ini berasal dari PDAM sehingga tidak dilakukan pemeriksaan bahan lagi.

\subsubsection{Tahap Perencanaan Proporsi Campuran}

Perencanaan proporsi campuran untuk beton berdasarkan metode Concrete Technology and Construction Practical Applications dan dengan bahan tambah naphthalene.

\subsubsection{Tahap Pengadukan}

Pada tahap ini dimana

pencampuran bahan berdasarkan berat dengan cara di timbang, kemudian pengadukan beton berdasarkan SNI 033976-1995 "Tata Cara Pengadukan Beton”

\subsubsection{Tahap Pembuatan Benda Uji}

Proses pembuatan benda uji pada penelitian ini sama seperti pembuatan beton konvensional dan ditambah bahan additive naphthalene. Benda uji dibuat dengan menggunakan cetakan berupa silinder dengan diameter $15 \mathrm{~cm}$ dan tinggi $30 \mathrm{~cm}$.

\subsubsection{Tahap Perawatan Benda Uji}

Setelah pembuatan benda uji selesai, untuk beton speedcrete cetakan dibuka sesuai umur yang sudah ditentukan dan tidak ada proses perawatan atau perendaman yaitu setelah cetakan di buka langsung dilakukan test uji kuat tekan ini untuk umur beton 12 jam, 18 jam, 24 jam, dan 48 jam, sedangkan untuk beton normal melalui proses perawatan setelah 24 jam, masing-masing cetakan dibuka dan benda uji dikeluarkan. Kemudian benda uji direndam dalam bak perendam berisi air yang telah memenuhi persyaratan untuk perawatan (curing) selama 28 hari.

\subsubsection{Tahap Pengujian Kuat Tekan Benda Uji}

Tahap pengujian kuat tekan benda uji untuk beton speedcrete pengujian dilakukan setelah cetakan dibuka, sedangkan untuk beton normal pengujian kuat tekan dapat dilakukan setelah tahap perawatan benda uji selesa. Prosedur pengujian kuat tekan dilakukan sesuan SNI 1974:2011 "Cara Uji Kuat Tekan Beton dengan Benda Uji Silinder".

\section{HASIL DAN PEMBAHASAN}

\subsection{Uji Pendahuluan}

\subsubsection{Agregat Halus dan Agregat Kasar}

Bahan yang digunakan pada penelitian ini adalah pasir beton dari Pontianakn dan kerikil dari Rumpin, Bogor. Langkah selanjutnya, sebagian dari bahan-bahan tersebut diteliti kadar lumpur, gradasi butir agregat, berat jenis dan kadar airnya. Hasil pengujian bahan yang telah dilakukan pada bahan dasar pembentuk beton berdasarkan SNI 03-1766-1990. 
Studi Kuat Tekan Beton... (Syifa/ hal. 67-75)

Hasil pengujian pendahuluan dapat dilihat pada Tabel berikut:

Tabel Hasil Pengujian Bahan

\begin{tabular}{|c|c|c|}
\hline Pengujian & Pasir & Kerikil \\
\hline $\begin{array}{c}\text { Kadar Lumpur } \\
\text { Butir }\end{array}$ & $1,36 \%$ & - \\
\hline Zat Organik & $\begin{array}{c}\text { Warna } \\
\text { No. } 1\end{array}$ & - \\
\hline $\begin{array}{c}\text { Berat Jenis dan } \\
\text { Penyerapan Air }\end{array}$ & 3,63 & 7,31 \\
\hline 1. BJ Kering & 2,42 & 2,45 \\
\hline 2. BJ SSD & 2,54 & 2,56 \\
\hline 3. BJ Semu & 2,73 & 2,76 \\
\hline 4. Penyerapan Air & 4,71 & 0,18 \\
\hline
\end{tabular}

\subsection{Perhitungan Rancangan Campuran Beton}

Perhitungan rancangan campuran beton ini dilakukan berdasarkan Concrete Technology and Construction Practical Applications tentang Mix Design for Special Purpose, sesuai dengan data-data hasil uji pemeriksaan agregat dan semen portland. Untuk campuran beton speedcrete dengan mutu yang direncanakan adalah fc' $35 \mathrm{MPa}$, dengan pertimbangan slump 80-100 mm, FAS 0,23 dan dari hasil uji penyerapan air, kadar lumpur dan berat jenis agregat maka proporsi masing-masing bahan penyusun beton (jelasnya pada Lampiran Mix Design) seperti Tabel berikut:

Tabel Proporsi Bahan Campuran Beton Speedcrete per-meter Kubik $\left(\mathrm{m}^{3}\right)$

Perencanaan perhitungan beton normal sama seperti beton speedcrete akan tetapi jumlah air ditambah $20 \%$ maka jumlah semen dan air ada peningkatan. Untuk campuran beton normal dengan mutu yang direncanakan adalah fc' 35 MPa, dengan pertimbangan slump $100 \pm 20$ $\mathrm{mm}$, FAS 0,3 dan dari hasil uji penyerapan air, kadar lumpur dan berat jenis agregat maka proporsi masing-masing bahan penyusun beton (jelasnya pada Lampiran Mix Design) seperti Tabel berikut:

\section{Tabel Proporsi Bahan Campuran Beton}

\begin{tabular}{|c|c|c|c|}
\hline \multicolumn{4}{|c|}{ Proporsi campuran kg/m³ } \\
\hline Semen & Air & Ag. Halus & $\begin{array}{c}\text { Ag. } \\
\text { Kasar }\end{array}$ \\
\hline 616 & 184,8 & 645 & 1046 \\
\hline
\end{tabular}

Normal per-meter Kubik $\left(\mathrm{m}^{3}\right)$

\subsection{Nilai Slump}

Nilai slump beton speedcrete bernilai $63 \mathrm{~cm}$. Slump speedcrete menghasilkan slump flow dengan 3 kali pengukuran yaitu $60 \mathrm{~cm}, 67 \mathrm{~cm}$ dan $63 \mathrm{~cm}$ menghasilkan rata-rata $63,33 \mathrm{~cm}$. Dan beton normal menggunakan uji slump yang biasa digunakan. Nilai slump beton normal adalah $14 \mathrm{~cm}$.

\subsection{Kuat Tekan}

Pengujian kuat tekan dilakukan untuk mendapatkan nilai kuat tekan dari benda uji yang telah dirancang kuat tekannya. Nilai kuat tekan yang didapat merupakan hasil dari beban maksimum yang diterima oleh benda uji dibagi dengan luas penampang benda uji. Data hasil pengujian kuat tekan beton untuk setiap perlakuan benda uji yang menggunakan temperatur curing berbeda dapat dilihat pada lampiran.

Hasil rata-rata kuat tekan beton dapat

\begin{tabular}{|c|c|c|c|c|}
\hline \multicolumn{5}{|c|}{ Proporsi campuran kg/m $\mathrm{m}^{3}$} \\
\hline Semen & Air & $\begin{array}{c}\text { Ag. } \\
\text { Halus }\end{array}$ & $\begin{array}{c}\text { Ag. } \\
\text { Kasar }\end{array}$ & $\begin{array}{c}\text { Additive } \\
\text { Naphthalene }\end{array}$ \\
\hline 598 & 137,5 & 645 & 1046 & $8,47 \mathrm{lt}$ \\
\hline
\end{tabular}


Studi Kuat Tekan Beton... (Syifa/ hal. 67-75)

dilihat pada tabel:

Tabel Hasil Kuat Tekan Beton Speedcrete

\begin{tabular}{|c|c|c|}
\hline $\begin{array}{l}\text { Umur } \\
\text { (Jam) }\end{array}$ & Sampel & $\begin{array}{c}\text { Kuat Tekan } \\
\text { (MPa) }\end{array}$ \\
\hline \multirow{3}{*}{12 Jam } & 1 & 0,64 \\
\hline & 2 & 0,39 \\
\hline & 3 & 0,4 \\
\hline \multicolumn{2}{|c|}{ Rata-rata } & 0.5 \\
\hline \multirow{3}{*}{$18 \mathrm{Jam}$} & 1 & 14,76 \\
\hline & 2 & 18,74 \\
\hline & 3 & 19,92 \\
\hline \multicolumn{2}{|c|}{ Rata-rata } & 17,81 \\
\hline \multirow{3}{*}{$24 \mathrm{Jam}$} & 1 & 30,33 \\
\hline & 2 & 29,5 \\
\hline & 3 & 33,6 \\
\hline \multicolumn{2}{|c|}{ Rata-rata } & 31,14 \\
\hline \multirow{3}{*}{$48 \mathrm{Jam}$} & 1 & 42,97 \\
\hline & 2 & 42,01 \\
\hline & 3 & 52,34 \\
\hline \multicolumn{2}{|c|}{ Rata-rata } & 45,77 \\
\hline
\end{tabular}

Tabel Hasil Kuat Tekan Beton Normal

\begin{tabular}{|c|c|c|}
\hline Umur (Hari) & Sampel & $\begin{array}{c}\text { Kuat Tekan } \\
(\mathrm{MPa})\end{array}$ \\
\hline 7 Hari & 1 & 44,39 \\
\hline & 2 & 43,36 \\
\hline & 3 & 38,06 \\
\hline \multicolumn{2}{|c|}{ Rata-rata } & 41,94 \\
\hline
\end{tabular}

\begin{tabular}{|c|c|c|}
\hline 14 Hari & 1 & 46,92 \\
\hline & 2 & 26,57 \\
\hline & 3 & 45,28 \\
\hline \multicolumn{2}{|c|}{ Rata-rata } & 39,59 \\
\hline 28 Hari & 1 & 51,86 \\
\hline & 2 & 53,48 \\
\hline & 3 & 54,54 \\
\hline \multicolumn{2}{|c|}{ Rata-rata } & 53,29 \\
\hline
\end{tabular}

\subsection{Pembahasan Penelitian}

Pembahasan berdasarkan data hasil penelitian yang telah dilakukan yaitu rancangan f'c $35 \mathrm{MPa}$ dengan menggunakan umur beton speedcrete 12 jam, 18 jam, 24 jam dan 48 jam.

Grafik kuat tekan seluruh benda uji dapat dilihat pada grafik berikut::

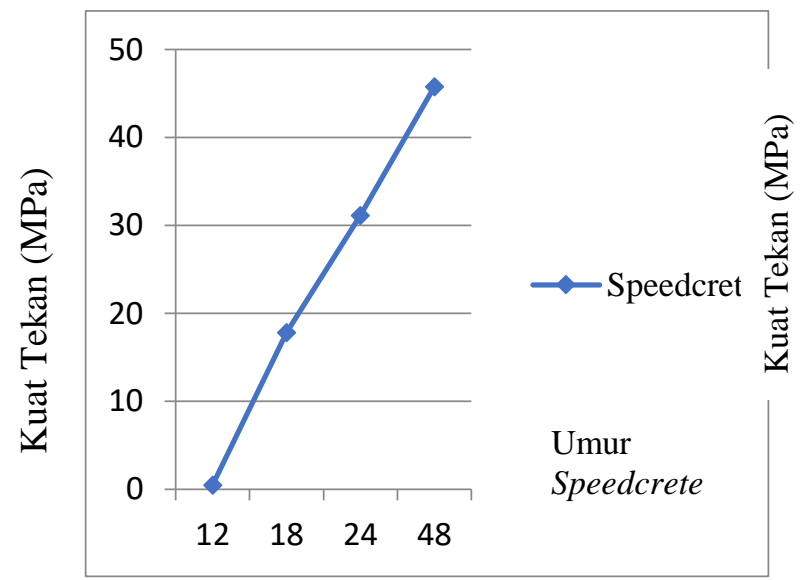

Gambar Grafik Kuat Tekan Rata-rata Beton Speedcrete

Sumber: Hasil Olahan Data 2017

Berdasarkan Gambar 4.3 nilai kuat tekan yang dihasilkan beton speedcrete mengalami terus peningkatan dengan hanya umur hitungan jam. Pada data gambar 4.3 diatas terlihat kenaikan nilai kuat tekan searah dengan kenaikan umur beton speedcrete pada umur 12 jam, 18 
jam, 24 jam, dan 48 jam. Beton speedcrete umur 12 jam menghasilkan nilai kuat tekan $0,5 \mathrm{MPa}$, umur 18 jam nilai kuat tekannya $17,81 \mathrm{MPa}$, dan pada umur 24 jam mutu yang dihasilkan belum sesuai atau hampir mendekati dengan mutu rencana fc' 35 $\mathrm{MPa}$ dengan rata-rata nilai kuat tekan beton speedcrete 31,14 MPa. Akan tetapi pada umur 48 jam masih mengalami kenaikan yang sangat tinggi dikarenakan selisih umur dua kali lipat dari 24 jam sehingga mencapai kuat tekan optimum.

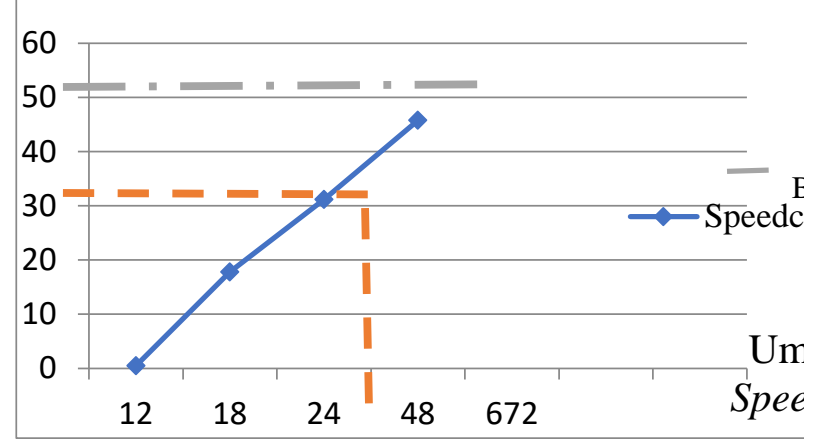

Gambar 4.4 Grafik Kuat Tekan Rata-rata

Beton Speedcrete dan Beton Normal

Sumber: Hasil Olahan Data 2017

Pada data grafik gambar 4.3 mengenai beton normal yang berumur 7 hari, dan 14 hari, dengan perencanaan mix design hampir sama seperti beton speedcrete hanya saja ada penambahan $20 \%$ air maka jumlah semen dan fas berbeda. Beton normal telah menghasilkan mutu yang tinggi bahkan melebihi mutu kuat tekan rencana fc' $35 \mathrm{MPa}$. Pada umur 7 hari hasil rata-rata mutu kuat tekan 41,94 MPa sedangkan di umur 14 hari rata-rata nilai kuat tekan $39,59 \mathrm{MPa}$ dan hasil ratarata mutu kuat tekan umur 28 hari yaitu 53,29 hari. Gambar grafik 4.3 menunjukan hasil nilai kuat tekan rencana fc' $35 \mathrm{MPa}$ pada beton speedcrete yaitu pada umur 33,5 jam dan mencapai kuat tekan optimum pada umur 48 jam. Sejalan dengan penelitian relevan tentang additive naphthalene bahwa dengan bertambahnya umur hasil nilai kuat tekan semakin meningkat dengan umur pengujian 3 hari 7 hari 14 hari dan 28 hari. Penelitian relevan lain tentang beton speedcrete dengan bahan tambah additive viscocrete -10 dengan bertambah nya umur hasil nilai kuat tekan juga semakin meningkat dengan umur penguijian 1 hari 3 hari 7 hari 14 hari dan 28 hari.

Pengujian nilai kuat tekan terhadap masing-masing benda uji dapat dilihat pada Gambar:
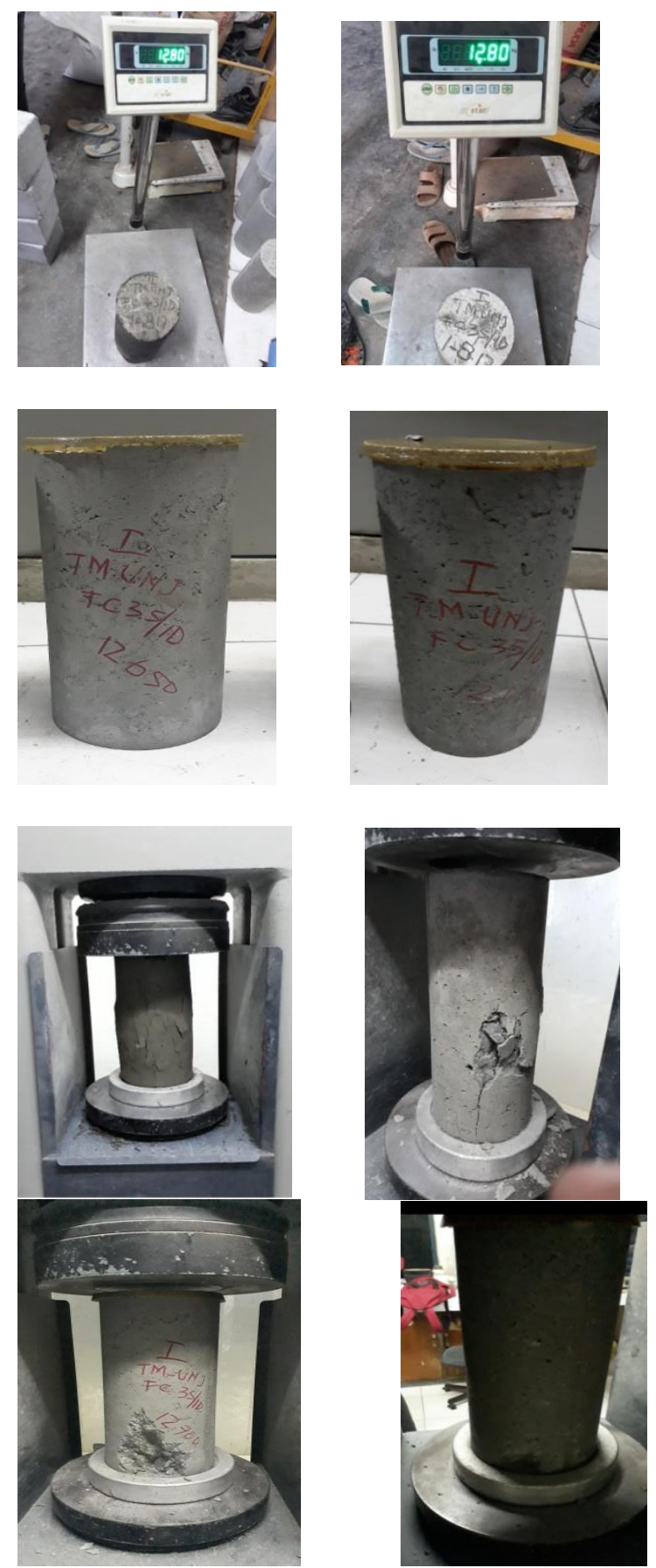

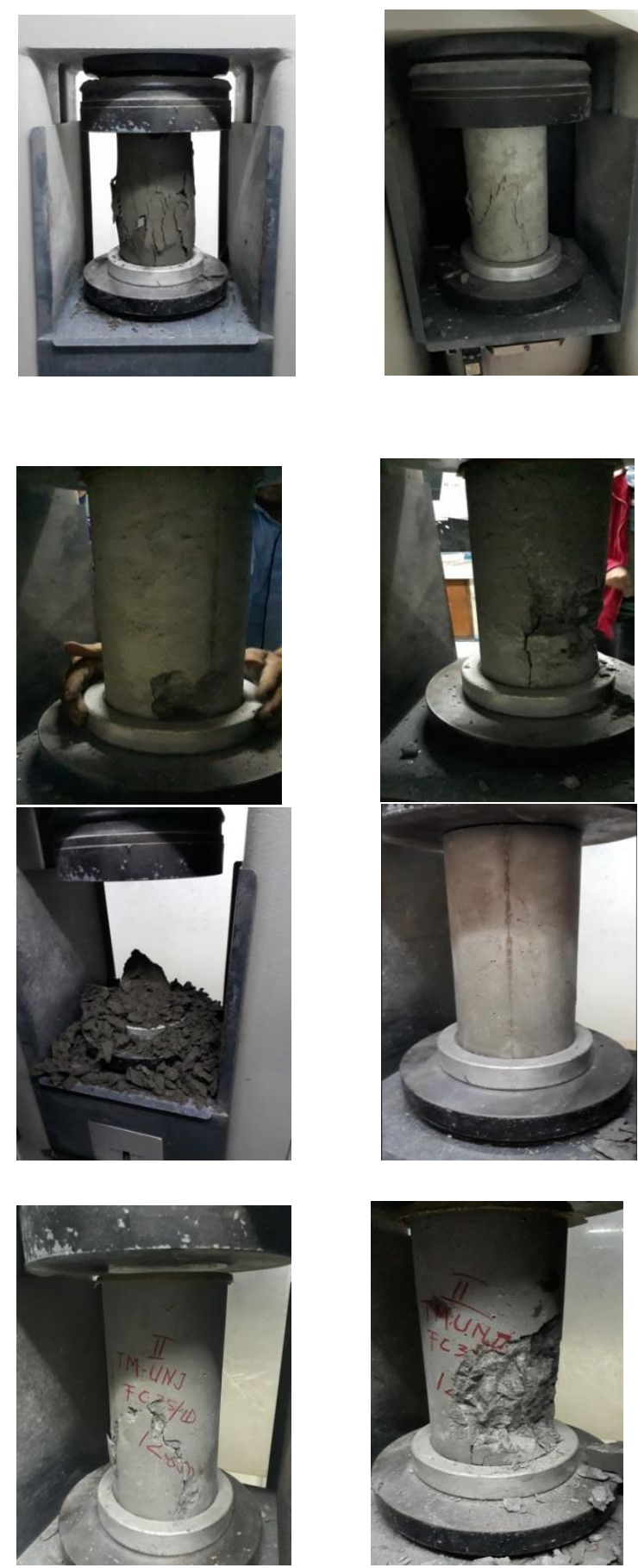

24 Jam

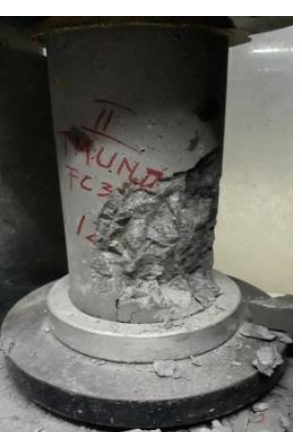

48 Jam

Gambar Pola Retak Beton Speedcrete dengan Umur 12 Jam, 18 Jam, 24 Jam, dan 48 Jam.

Sumber: Dokumentasi Pribadi 2017

Pola retak beton speedcrete umur 12 jam bahkan sudah mencapai hancur dikarenakan kondisi beton yang masih

lembab dan belum cukup untuk dilakukan pengujian kuat tekan, ditunjukan dengan hasil nilai kuat tekan rata-rata kecil yaitu 0,5 Mpa dan hanya mencapai 2\% dari kuat tekan rencana. Pola retak beton speedcrete umur 18 jam adalah terdapat retak dibagian tengah, speedcrete tersebut sudah mengalami kenaikan nilai kuat tekan sebesar 17,81 MPa yaitu mencapai 50\% namun masih menunjukan belum optimal fungsi dari additive naphthalene yang mengurangi kadar air dan meningkatkan mutu.

Pola retak beton speedcrete umur 24 jam yaitu retak dibagian bawah beton tidak terlalu besar retakannya dan mengalami kenaikan nilai kuat tekan hampir $90 \%$ namun belum mencapai kuat tekan rencana fc' $35 \mathrm{MPa}$ dan dibandingkan dengan beton normal fc' 35 MPa. Pola retak beton speedcrete umur 48 jam dengan selisih umur dari sebelumnya dua kali lipat menghasilkan retakan yang hampir sama seperti sebelumnya yaitu retak dibagian bawah beton, namun nilai kuat tekan yang dihasilkan meningkat tinggi mencapai 45,77 MPa yaitu $110 \%$ ini menunjukan additive naphthalene dapat berfungsi secara optimal. Untuk mencapai mutu fc' $35 \mathrm{MPa}$ pada beton speedcrete dengan memakai interpolasi maka hasilnya umur 33,5 Jam.

\section{KESIMPULAN}

1. Beton speedcrete dengan bahan tambah additive naphthalene dengan dosis pemakaian $1,7 \%$ dari berat semen, mencapai nilai kuat tekan rencana fc' $35 \mathrm{MPa}$ pada umur 33,5 jam.

2. Kuat tekan beton speedcrete dengan bahan tambah additive naphthalene pada umur 12 jam, 18 jam, 24 jam, dan 48 jam menghasilkan kuat tekan 0,5 $\mathrm{MPa}, 17,81 \mathrm{MPa}, 31,14 \mathrm{MPa}$, dan 45,77 MPa. Sedangkan beton normal tanpa bahan tambah additive pada umur 7 hari, 14 hari, dan 28 hari 
menghasilkan kuat tekan 41,94 $\mathrm{MPa}$, 39,59 $\mathrm{MPa}$, dan 53,29 $\mathrm{MPa}$.

3. Adanya peningkatan umur beton speedcrete maka masih terjadi adanya peningkatan nilai kuat beton speedcrete, bahkan dapat melebihi kuat tekan rencana.

4. Additive naphthalene berfungsi dengan baik sehingga menghasilkan mutu yang tinggi, dan mengurangi kadar air.

5. Beton speedcrete sudah cepat mengeras di umur 18 jam, tetapi mutu belum tercapai

\section{DAFTAR PUSTAKA}

Gusva, D.W. 2013. Seyawa Aromatik Naftalena

http://dhaniwindragusva.blogspot.co. $\mathrm{id} / 2013 / 11 /$ senyawa-aromatiknaftalena.html Diakses pada 18 Maret 2017.

Hayyu, S. 2009. Speedcrete Inovasi Beton dengan Initial Set Kilat http://Sagabanget.wordpress.com/20 09/09/09/speedcrete-inovasi-betondengan-initial-set-kilat/ Diakses pada 18 Maret 2017.

Kuat Tekan Beton Normal. [jurnal]. Jakarta: Fakultas Teknik, Universitas Muhammadiyah Jakarta.

Pei, C.2017. Mechanism of Naphthalene Series Superplasticizer https://www.linkedin.com/pulse/mec hani m-naphthalene-seriessuperplasticizer-pei-chinacayc Diakses pada 18 Maret 2017.

Seti dan Nadia. 2012. Analisis Pengaruh Beton dengan Bahan Admixture Naphthalene da Polycarboxilate Terhadap

SNI 2458:2008 Tentang Tata Cara Pengambilan Contoh Beton Segar.
Susandi, I. 2013. Tinjauan Kuat Tekan Beton Ringan Menggunakan Mix Design Speedcrete dengan Bahan Tambah Sika

Viscocrete-10 [skripsi]. Surakarta: Fakultas Teknik, Universitas Muhammadiyah Surakarta. 